\title{
Erfolgsmarke feiert 15-jähriges Jubiläum
}

3M war der 1. Dentalhersteller, der ein Zirkoniumoxid-System mit Färbelösungen entwickelte. Heute ist Lava Zirkoniumoxid eines der am häufigsten im Rahmen von Studien untersuchten dentalen Oxidkeramiken, die derzeit auf dem Markt erhältlich sind. In den ersten 15 Jahren ihres klinischen Einsatzes wurde Lava zu einer etablierten Marke im Dentalmarkt. Das Unternehmen hat in dieser Zeit aber auch Optimierungen vorangetrieben und war der erste Anbieter, der eine Übereinstimmung der Färbeflüssigkeiten mit allen 16 VITA Classic-Farben erreichte. Mit der Einführung von Lava Plus hochtransluzentes Zirkoniumoxid als Ronde ist Zirkoniumoxid der Marke Lava heute einfacher zugänglich als je zuvor.

Nach einer Pressemitteilung der 3M Deutschland GmbH, Neuss

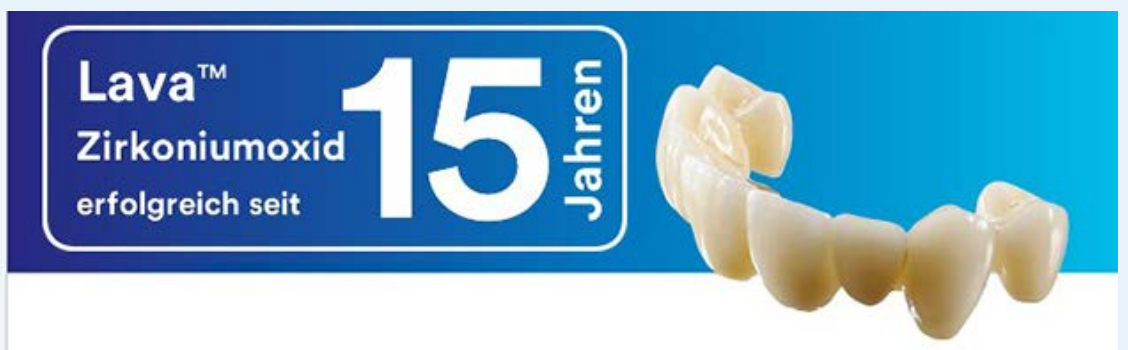

